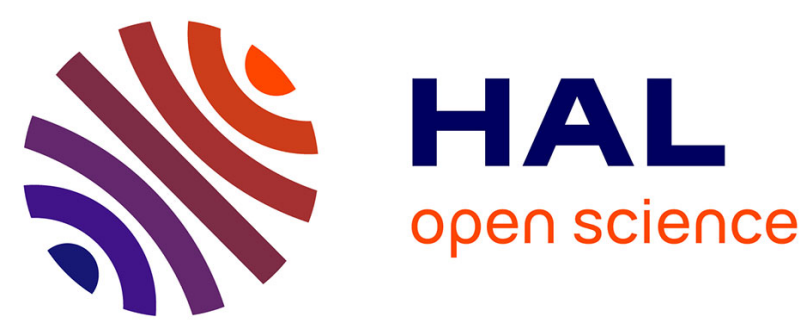

\title{
Chronic pelvic pain and rectal prolapse invite consideration of enterocele
}

C Brochard, A Ropert, M Chambaz, C Gouriou, C Cardaillac, T Grainville, G Bouguen, L Siproudhis

\section{- To cite this version:}

C Brochard, A Ropert, M Chambaz, C Gouriou, C Cardaillac, et al.. Chronic pelvic pain and rectal prolapse invite consideration of enterocele. Colorectal Disease, 2020, 22 (3), pp.325-330. 10.1111/codi.14877 . hal-02365041

\section{HAL Id: hal-02365041 https://hal-univ-rennes1.archives-ouvertes.fr/hal-02365041}

Submitted on 9 Dec 2019

HAL is a multi-disciplinary open access archive for the deposit and dissemination of scientific research documents, whether they are published or not. The documents may come from teaching and research institutions in France or abroad, or from public or private research centers.
L'archive ouverte pluridisciplinaire HAL, est destinée au dépôt et à la diffusion de documents scientifiques de niveau recherche, publiés ou non, émanant des établissements d'enseignement et de recherche français ou étrangers, des laboratoires publics ou privés. 
DR CHARLENE BROCHARD (Orcid ID : 0000-0001-7354-6301)

Article type : Original Article

\section{CHRONIC PELVIC PAIN AND RECTAL PROLAPSE INVITE CONSIDERATION OF ENTEROCELE}

Charlène Brochard ${ }^{1,2,3,4}$, Alain Ropert ${ }^{2,4}$, Marion Chambaz ${ }^{2}$, Claire Gouriou ${ }^{1}$, Claire Cardaillac $^{5}$, Thomas Grainville ${ }^{1}$, Guillaume Bouguen ${ }^{1,3,4}$, Laurent Siproudhis Th $^{1,3,4}$

${ }^{1}$ Service des Maladies de l'Appareil Digestif, CHU Pontchaillou, Université de Rennes 1, Rennes, France

2 Services d'Explorations Fonctionnelles Digestives, CHU Pontchaillou, Université de Rennes 1, Rennes, France

${ }^{3}$ INSERM U1241, Equipe EXPRES, Université de Rennes 1, Rennes, France

${ }^{4}$ CIC 1414, INPHY, Université de Rennes 1, Rennes, France

${ }^{5}$ Service de gynécologie-obstétrique et médecine de la reproduction, hôpital Mère-Enfant,

CHU de Nantes, Nantes, France

Short running head title: enterocele and pelvic pain

\section{Correspondence to:}

Charlène Brochard

Service d'Explorations Fonctionnelles Digestives, Service des Maladies de l'Appareil Digestif

2 rue Henri le Guillou

35033 Rennes Cedex, FRANCE 
Telephone (0033)-2-99-28-43-11 / Fax (0033)-2-99-28-41-04

Email: charlene.brochard@chu-rennes.fr

\section{Disclaimers:}

GB received lecture fees from Abbvie, Ferring, MSD, Takeda and Pfizer and consultant fees from Takeda, Janssen. LS received lecture fees from Abbvie, Ferring and MSD. LS received consultant fees from Takeda and Ferring. CB received lecture fees from Ipsen. AR, MC, CG, $\mathrm{CC}$ and TG have no conflicts of interest

Source of Funding: There was no funding.

Word count (excluding title page, abstract, references, table and figure): 2024 words.

Word count of abstract: 235 words.

Authors' contributions: Study concept and design: CB, GB and LS; acquisition of data: CB, $\mathrm{AR}, \mathrm{MC}, \mathrm{CG}, \mathrm{CC}$, TG and LS; analysis and interpretation of data: CB and LS; drafting of the manuscript: $\mathrm{CB}$, and LS; critical revision of the manuscript for important intellectual content: AR, MC, CG, CC, TG, GB and LS. All authors reviewed the paper and approved the final submitted version. 


\section{ABSTRACT}

Aim: Data on the pathogenesis and symptoms of enterocele are limited. The objectives of this study were to determine the clinical phenotype of patients with enterocele, to highlight the main functional and/or anatomic associations and to improve the accuracy of the preoperative assessment of pelvic floor disorders.

Method: A total of 588 patients who were referred to a tertiary unit for an anorectal complaint underwent self-administered questionnaires, physical examination, anorectal manometry and defecography. Enterocele was defined using defecography as a radiological hernia of the small bowel into an enlarged rectovaginal space. One hundred and thirty-five patients with enterocele were age and gender-matched with 270 patients without enterocele. Factors associated with enterocele were assessed using univariate and multivariate analysis models.

Results: Patients with enterocele were less frequently obese than patients without enterocele (8/135 vs $36 / 270, p=0.02)$ and more frequently had a past history of pelvic surgeries $(51 / 135$ vs $75 / 270, \mathrm{p}=0.04)$. They complained more frequently of pelvic pain on bearing down (29/135 vs 24/270, $\mathrm{p}=0.003)$, anal procidentia ( $37 / 135$ vs $46 / 270, \mathrm{p}=0.01)$ and more frequently had irritable bowel syndrome (IBS) (83/135 vs 131/270, $\mathrm{p}=0.01$ ) and severe constipation according to the Kess score $(104 / 135$ vs $182 / 270, \mathrm{p}=0.04)$. Anorectal function was comparable between the two groups. Patients with enterocele had more frequent rectoceles and overt rectal prolapses compared to patients without enterocele.

Conclusions: Enterocele should be investigated in patients with chronic pelvic pain, overt rectal prolapse and/or a past history of pelvic surgery.

\section{What does this paper add to literature?}


This paper highlights that patients with enterocele more frequently had rectal prolapse and complaints of pelvic pain. These features should draw attention to the possibility of enterocele, and conventional defecography should be considered.

\section{INTRODUCTION}

Enterocele is defined as the descent of the small intestine into the lower pelvic cavity, where it interposes in the rectovaginal septum. The positive predictive value of the clinical diagnosis of enterocele is poor [1], and radiological examinations are mandatory to diagnose enterocele. Most prefer conventional defecography over dynamic magnetic resonance defecography $[2,3]$. However, not all centers have access to conventional defecography. Indirect assessments of complaints, clinical evaluation and anorectal manometry are poorly reported.

Studies focusing on enterocele are scarce, except in reported gynecological experiences [46]. Few studies were performed by colorectal surgeons [7,8]. Surgical correction of pelvic floor disorders may be modified by the occurrence of an enterocele identified during preoperative assessment [9]. Therefore, adequate pre-operative diagnosis of enterocoeles is important.

The present study assessed the clinical and pathophysiologic features encountered in patients with enterocele in a case-matched study. Our aims were to determine the clinical phenotype of patients with enterocele, to highlight the main functional and/or anatomic associations, and finally to improve the accuracy of the preoperative assessment of pelvic floor disorders. 


\section{SUBJECTS AND METHODS}

\section{Study Population}

All patients in this study had been referred to a tertiary unit (University Hospital, Rennes, France) between 2005 and 2015 for an anorectal complaint. Details were prospectively included in a dedicated database (Fondamentum, CNIL no. 1412467). Anorectal complaints were listed as follows: pelvic pain, bearing down, anal procidentia, dyschezia (sensation of blockage at defecation, sensation of incomplete evacuation, straining during defecation), mucus discharge, anal bleeding, self-reported faecal incontinence. All patients completed self-administered questionnaires, physical examination, anorectal manometry and defecography. Patients were excluded if they were pregnant or had a history of pelvic radiation, inflammatory bowel disease, anal or rectal cancer, or anal or rectal stricture.

\section{Functional assessment and anorectal testing}

Self-administered questionnaires, physical examination, anorectal manometry, and defecography were recorded in a database. All procedures were performed at the same time. Age, sex, height, weight, medical history (including diabetes, neurological disease, and depression), and surgical and obstetrical histories were recorded. Past history of pelvic surgery was differentiated into hysterectomy, surgery of posterior colpocele, surgery of anterior colpocele and colpopexy. Symptoms were recorded as previously described [10-12]. 
The questionnaire focused on the following anorectal complaints: pelvic pain, bearing down, anal or genital procidentia, and digitation. It also included a stool diary using the Bristol stool chart. All patients had had their complaints for at least 6 months. Irritable bowel syndrome (IBS) was defined according to the Rome III criteria [12]. The subtype of IBS was defined using the stool diary, and a physician recorded it in the database during the consultation. Clinical dyssynergic defecation and the presence of an enterocele on clinical examination were recorded. Clinical dyssynergy defecation was defined as a contraction during effort. Fecal incontinence was assessed according to the validated Cleveland Clinic Incontinence Score (CCIS) [13] and was defined as CCIS >5 [14]. Assessment of constipation was performed using the validated Knowles-Eccersley-Scott Symptom Constipation Score (KESS) [15]. Quality of life was quantified using a validated scale for gastrointestinal complaints (Gastrointestinal Quality of Life Index (GIQLI)) [16], as previously published in studies of fecal incontinence cohorts $[11,17]$.

Anorectal manometry was performed as previously described [17-19]. To record the mean maximal resting pressures in the upper and lower anal canals and anal canal length, anal canal pressures were monitored using a three-lumen water-perfused catheter assembly (R3B, Mui Scientific, Mississauga, Ontario, Canada) with radially distributed side holes. Each of the three lumens was perfused at a rate of $1 \mathrm{~mL} / \mathrm{min}$ with distilled water from an electrically powered compressed pneumohydraulic perfusion system (PIP4-4, Mui Scientific, Mississauga, Ontario, Canada). The mean squeeze pressure in the lower anal canal was obtained during a 30-second squeeze. Amplitude contraction was the variation between the resting pressures and maximal pressures during the contraction. Dyssynergic defecations were recorded during effort. Rectal perception thresholds were recorded using isovolumic distension with balloon air inflation.

Defecography was performed as previously described using barium contrast medium 
(Microtrast) via oral, vaginal, and anal routes [20]. The bladder was not catheterized. Rectal filling was sufficient to materialize the sigmoid loop. The ileum was filled via the oral intake of barium (Micropaque) 90 minutes before radiological examination. This radiological examination allowed the diagnosis of enterocele, rectocele, high-grade prolapse, perineal descent, paradoxical puborectalis contraction and rectal emptying. Enterocele was defined as a radiological hernia of the small bowel into an enlarged rectovaginal space, as previously described [21]. The severity of the enterocele was classified as previously [22]. Perineal descent was quantified as the maximal length that separated the upper anal canal site and pubococcygeal line during defecation [23]. Paradoxical puborectalis contraction was defined as the absence of descent or an enlargement of the puborectalis muscle during straining.

\section{Study design and definitions}

Following these investigations, consecutive patients with enterocele diagnosed by defecography were compared with two age- and sex-matched patients without enterocele who were observed during the same period of time. Constipation was defined as a KESS score $>9$ [15]. Severe incontinence was defined as a CCIS >8, as described previously [14].

\section{Statistical analysis.}

Data were prospectively collected and studied retrospectively. Data are expressed as the means \pm standard deviation (SD) or medians (range) if not normally distributed. Comparisons between patients with enterocele with patients without enterocele were performed using ttests for normally distributed variables, the Wilcoxon test for non-normally distributed variables and the chi-squared test or Fisher's exact test for categorical variables. For each analysis, a P-value $<0.05$ was considered to be statistically significant. Items with $\mathrm{p}<0.05$ by univariate analysis were integrated into a binary logistic regression model for multivariate analysis. When there were several significant and mutually dependent variables in univariate 
analysis, only one was integrated into the multivariate analysis. The results are shown as odds ratios (ORs) with 95\% confidence intervals [CIs]. Statistical analyses were performed using JMP Pro Software, version 13.0.0 (SAS Institute Inc., Cary, NC, USA).

\section{RESULTS}

\section{Population}

From 2005 to 2015, 588 patients who underwent self-administered questionnaires, physical examination, anorectal manometry, and defecography during a single visit were included in the registry and recorded in the prospective database. A total of 135 patients with enterocele were eligible. These patients were case-matched in age and gender with 270 patients without enterocele. The characteristics of the 405 patients are depicted in Table 1.

Patients without enterocele had a higher body mass index (BMI) and were more frequently obese than patients with enterocele. Overall, 24/385 (6.2\%) patients were underweight (BMI $\left.<18.5 \mathrm{~kg} / \mathrm{m}^{2}\right)$, and 9/127 (7.1\%) patients with enterocele were underweight. No patient had bariatric surgery. The two groups did not differ according to medical histories. Past history of pelvic surgeries was significantly more frequent in patients with enterocele. Past history of hysterectomy was significantly more frequent in patients with enterocele. Among the 90 patients who had hysterectomy, 30 patients had vaginal hysterectomy, and 60 patients had laparoscopic hysterectomy. The surgical approach of the hysterectomy was not associated with enterocele.

With regard to the clinical characteristics, patients with enterocele complained more frequently of pelvic pain or bearing down and anal procidentia and more frequently suffered from irritable bowel syndrome (IBS), particularly constipation-IBS (56/135 (41.5\%) vs. $73 / 270(27.0 \%) ; \mathrm{p}=0.0033)$. Patients with enterocele more frequently used digital assistance. Of the 135 patients with a radiological enterocele, the diagnosis was clinically suspected in 
only 43 patients $(31.8 \%)$. The positive and negative predictive values of clinical examination to diagnose enterocele were $100 \%$ and $74.6 \%$, respectively.

Severity of fecal incontinence and quality of life, according to CCIS and GIQLI, were comparable between patients with and without enterocele. Patients with an enterocele more frequently suffered severe constipation according to the Kess score.

\section{Anorectal function and associated pelvic floor disorders}

The results of the anorectal manometry and defecography are depicted in Table 2. Anorectal function was comparable between the two groups. In the 129 patients confirmed as having an enterocoele, $69(50.4 \%)$ had a grade II and 64(49.6\%) a grade III enterocoele. Enterocele severity was not associated with pelvic pain, bearing down, genital procidentia or digital assistance. Procidentia was more common in patients with Grade III than Grade II enterocele (26/64 vs $10 / 65, p=0.0014)$. No enterocele containing sigmoid loop was identified. Patients with enterocele had more frequent rectoceles and overt rectal prolapses compared to patients without enterocele, and, in addition were more likely to have resting and perineal descent. Complete rectal emptying was also less frequent.

\section{Factors associated with enterocele}

A multivariate analysis including past history of pelvic surgery, pelvic pain and/or bearing down, digital assistance, IBS, KESS score > 9 and overt rectal prolapse revealed that the factors significantly associated with enterocele were past history of pelvic surgery $(\mathrm{OR}=2.00$ [1.23-3.27], $\mathrm{p}=0.0056)$, pelvic pain and/or bearing down $(\mathrm{OR}=3.06[1.60-5.84], \mathrm{p}=0.0007)$ and overt rectal prolapse $(\mathrm{OR}=3.10$ [1.95-4.92], $\mathrm{p}=0.0001)$.

\section{DISCUSSION}

The results of this prospective case matched study describe the clinical and 
physiopathological features encountered in patients with enterocele.

Our results suggest that a past history of pelvic surgery and pelvic pain and/or bearing down predispose to the development of a rectocele. Overt rectal prolapse was a frequently associated event in patients with enterocele. Manometric data do not aid the diagnosis of suspected enterocele.

The main strengths of this study are that it was a nonsurgical case-matched study that included a large cohort of patients. The data were prospectively recorded in a database using recommended classifications and validated scales [13,15,16]. All examinations were performed following the same procedure. Nonetheless, our results should be interpreted with caution for several reasons. Firstly, it was a retrospective analysis of data collected prospectively and some data, especially BMI, were lacking. Secondly, we had had no followup evaluations and we don't know if surgical treatment of an enterocele improves pain. Thirdly, our population may not be typical as recruitment was to a tertiary center that specializes in anorectal disorders and might predispose to patients with more severe symptoms.

The association between enterocele and a past history of pelvic floor surgery, in particular hysterectomy, has been previously described [4,6,24-26]. The creation of an anatomic dehiscence anterior to the rectum may explain the occurrence of enterocele after hysterectomy. This point raises questions for guidance for hysterectomy. The associations between enterocele and overt rectal prolapse and enterocele and rectocele were high $(60.7$ and $27.4 \%$, respectively). These data are comparable with the literature [26]. Our higher rate in patients with overt rectal may reflect our extensive preoperative investigations. Taken 
together, this suggests that all patients with an enterocoele should be investigated for concomitant posterior pelvic floor disorder.

Patients with enteroceles experienced severe constipation-IBS symptoms according to the Kess score, and experienced incomplete rectal emptying more frequently and needed to use digital assistance more often. These data suggest an association between constipation and rectal evacuation disorders and enterocele. This result is consistent with the literature [27]. Whether constipation is an etiological factor or a consequence of the enterocele is not clear.

The association between pelvic pain and enterocele has not been extensively discussed in the literature. Pelvic pain may be partially explained by the mechanical stresses induced by perineal descent. Recent studies on the pathophysiology of pain in patients with inguinal hernia demonstrated that the mechanism of pain in inguinal hernia may be related to compressive neuropathy $[28,29]$. These data are likely to change the management of pain with inguinal hernia. Indeed, early surgery prevents postoperative pain. Neuropathy damage may also partially explain pelvic pain in patients with enterocele. Few studies evaluated the effect of enterocele repair on symptoms [30,31]. Short-term follow-up (3 months) has shown that enterocele repair is beneficial but one of four patients encounters recurrent symptoms of pelvic discomfort in the long term [30,31]. Regarding to the pain, half of the patients were improved in the long term but 10/54 complained of pain after surgery [31].

Prospective studies assessing the change in specific symptoms after surgical correction of enterocele are needed to confirm this hypothesis.

In conclusion, patients with enterocele more frequently had a past history of pelvic surgery, complaints of pelvic pain and rectal prolapse. These features should draw attention to the 
possibility of enterocele, and conventional defecography should be considered. The treatment for constipation and early surgical correction of enterocele needs further evaluation.

\section{REFERENCES}

1. Siproudhis L, Ropert A, Vilotte J, Bretagne JF, Heresbach D, Raoul JL, et al. How accurate is clinical examination in diagnosing and quantifying pelvirectal disorders? A prospective study in a group of 50 patients complaining of defecatory difficulties. Dis Colon Rectum. 1993;36:430- 8.

2. Faucheron J-L, Barot S, Collomb D, Hohn N, Anglade D, Dubreuil A. Dynamic cystocolpoproctography is superior to functional pelvic MRI in the diagnosis of posterior pelvic floor disorders: results of a prospective study. Colorectal Dis Off J Assoc Coloproctology G B Irel. 2014;16:O240-247.

3. van Iersel JJ, Formijne Jonkers HA, Verheijen PM, Broeders I a. MJ, Heggelman BGF, Sreetharan V, et al. Comparison of dynamic magnetic resonance defaecography with rectal contrast and conventional defaecography for posterior pelvic floor compartment prolapse. Colorectal Dis Off J Assoc Coloproctology G B Irel. 2017;19:O46-53.

4. Symmonds RE, Williams TJ, Lee RA, Webb MJ. Posthysterectomy enterocele and vaginal vault prolapse. Am J Obstet Gynecol. 1981;140:852-9.

5. Maillard E, Henry L, Mion F, Barth X, Tissot E, Mellier G, et al. Elytrocele with and without a history of hysterectomy (303 defecography studies). Gastroenterol Clin Biol. 2008;32:953-9.

6. Timmons MC, Addison WA, Addison SB, Cavenar MG. Abdominal sacral colpopexy in 163 women with posthysterectomy vaginal vault prolapse and enterocele. Evolution of operative techniques. J Reprod Med. 1992;37:323-7.

7. Mege D, Sans A, Maignan A, Duclos J, Frasconi C, Le Huu Nho R, et al. Temporary successful results of ventral rectopexy for enterocele surgical correction, about 138 patients. Int J Colorectal Dis. 2017;32:1569-75.

8. Mäkelä-Kaikkonen J, Rautio T, Pääkkö E, Biancari F, Ohtonen P, Mäkelä J. Robotassisted vs laparoscopic ventral rectopexy for external or internal rectal prolapse and enterocele: a randomized controlled trial. Colorectal Dis Off J Assoc Coloproctology G B Irel. 2016;18:1010-5.

9. Faucheron J-L, Voirin D, Riboud R, Waroquet P-A, Noel J. Laparoscopic anterior rectopexy to the promontory for full-thickness rectal prolapse in 175 consecutive patients: short- and long-term follow-up. Dis Colon Rectum. 2012;55:660-5.

10. Favreau C, Siproudhis L, Eleouet M, Bouguen G, Bretagne J-F. Underlying functional bowel disorder may explain patient dissatisfaction after haemorrhoidal surgery. Colorectal Dis Off J Assoc Coloproctology G B Irel. 2012;14:356-61.

11. Brochard C, Bouguen G, Bodère A, Ropert A, Mallet A-L, Morcet J, et al. Prospective cohort study of phenotypic variation based on an anal sphincter function in adults with fecal incontinence. Neurogastroenterol Motil Off J Eur Gastrointest Motil Soc. 2016; 12. Longstreth GF, Thompson WG, Chey WD, Houghton LA, Mearin F, Spiller RC. Functional bowel disorders. Gastroenterology. 2006;130:1480-91. 
13. Jorge JM, Wexner SD. Etiology and management of fecal incontinence. Dis Colon Rectum. 1993;36:77-97.

14. Brochard C, Peyronnet B, Dariel A, Ménard H, Manunta A, Ropert A, et al. Bowel Dysfunction Related to Spina Bifida: Keep It Simple. Dis Colon Rectum. 2017;60:1209-14. 15. Knowles CH, Eccersley AJ, Scott SM, Walker SM, Reeves B, Lunniss PJ. Linear discriminant analysis of symptoms in patients with chronic constipation: validation of a new scoring system (KESS). Dis Colon Rectum. 2000;43:1419-26.

16. Eypasch E, Williams JI, Wood-Dauphinee S, Ure BM, Schmülling C, Neugebauer E, et al. Gastrointestinal Quality of Life Index: development, validation and application of a new instrument. Br J Surg.1995;82:216-22.

17. Brochard C, Vénara A, Bodère A, Ropert A, Bouguen G, Siproudhis L.

Pathophysiology of fecal incontinence in obese patients: A prospective case-matched study of 201 patients. Neurogastroenterol Motil Off J Eur Gastrointest Motil Soc. 2017;29.

18. Brochard C, Siproudhis L, Ropert A, Mallak A, Bretagne J-F, Bouguen G. Anorectal dysfunction in patients with ulcerative colitis: impaired adaptation or enhanced perception? Neurogastroenterol Motil Off J Eur Gastrointest Motil Soc.2015;27:1032-7.

19. Siproudhis L, Bellissant E, Juguet F, Allain H, Bretagne JF, Gosselin M. Effects of cholinergic agents on anorectal physiology. Aliment Pharmacol Ther. 1998;12:747-54.

20. Siproudhis L, Ropert A, Lucas J, Raoul JL, Heresbach D, Bretagne JF, et al.

Defecatory disorders, anorectal and pelvic floor dysfunction: a polygamy? Radiologic and manometric studies in 41 patients. Int J Colorectal Dis. 1992;7:102-7.

21. Halligan S, Bartram C, Hall C, Wingate J. Enterocele revealed by simultaneous evacuation proctography and peritoneography: does « defecation block » exist? AJR Am J Roentgenol. 1996;167:461-6.

22. Wallenhorst T, Bouguen G, Brochard C, Cunin D, Desfourneaux V, Ropert A, et al. Long-term impact of full-thickness rectal prolapse treatment on fecal incontinence. Surgery. 2015;158:104-11.

23. Shorvon PJ, McHugh S, Diamant NE, Somers S, Stevenson GW. Defecography in normal volunteers: results and implications. Gut. 1989;30:1737-49.

24. Mellgren A, Johansson C, Dolk A, Anzén B, Bremmer S, Nilsson BY, et al. Enterocele demonstrated by defaecography is associated with other pelvic floor disorders. Int J Colorectal Dis. 1994;9:121-4.

25. Chou Q, Weber AM, Piedmonte MR. Clinical presentation of enterocele. Obstet Gynecol. 2000;96:599-603.

26. Lapalus M-G, Henry L, Barth X, Mellier G, Gautier G, Mion F, et al. [Enterocele: clinical risk factors and association with others pelvic floor disorders (about 544 defecographies)]. Gynecol Obstet Fertil. 2004;32:595-600.

27. Holley RL. Enterocele: a review. Obstet Gynecol Surv.1994;49:284-93.

28. Wright R, Born DE, D'Souza N, Hurd L, Gill R, Wright D. Pain and compression neuropathy in primary inguinal hernia. Hernia J Hernias Abdom Wall Surg. 2017;21:715-22. 29. Wright R, Born DE, D’Souza N, Hurd L, Gill R, Wright D. Why do inguinal hernia patients have pain? Histology points to compression neuropathy. Am J Surg. 2017;213:975- 82 . 
30. Oom DM, van Dijl VR, Gosselink MP, van Wijk JJ, Schouten WR.Enterocele repair by abdominal obliteration of the pelvic inlet: long-term outcome on obstructed defaecation and symptoms of pelvic discomfort.Colorectal Dis. 2007;9:845-50.

31. Jean F, Tanneau Y, Le Blanc-Louvry I, Leroi AM, Denis P, Michot F. Treatment of enterocele by abdominal colporectosacropexy - efficacy on pelvic pressure. Colorectal Dis 2002; 4: 321-5.

\section{Table 1 : Details of Patients}

\begin{tabular}{|c|c|c|c|c|}
\hline & & & & \\
\hline & All $(N=405)$ & Enterocele $(N=135)$ & No enterocele $(N=270)$ & \\
\hline Variable & $N(\%)$ or mean $(\mathrm{SD})$ & $N(\%)$ or mean (SD) & $N(\%)$ or mean (SD) & P-value \\
\hline Age (years) & $57.5(15.1)$ & $57.6(15.1)$ & $57.4(15.1)$ & 0.91 \\
\hline Female/male sex (ratio F/M) & $375 / 30(92.6 / 7.4)$ & $125 / 10(92.6 / 7.4)$ & $250 / 20(92.6 / 7.4)$ & 1.00 \\
\hline BMI $\left(\mathrm{Kgs} / \mathrm{m}^{2}\right)$ & $24.2(4.6)$ & $23.1(4.0)$ & $24.7(4.8)$ & 0.001 \\
\hline Obesity $\left(\mathrm{BMI}>30 \mathrm{Kgs} / \mathrm{m}^{2}\right)$ & $44(10.9)$ & $8(5.9)$ & $36(13.3)$ & 0.02 \\
\hline Diabetes & $11(2.7)$ & $2(1.5)$ & $9(3.3)$ & 0.28 \\
\hline Neurological disease & $55(13.6)$ & $17(12.6)$ & $38(14.1)$ & 0.68 \\
\hline $\begin{array}{c}\text { Depression/ Antidepressant } \\
\text { treatment }\end{array}$ & $71(17.5)$ & $26(19.3)$ & 45 (16.7) & 0.52 \\
\hline Past treatments & & & & \\
\hline Cholecystectomy & $39(9.6)$ & $16(11.9)$ & $23(8.5)$ & 0.28 \\
\hline Surgery of anterior colopocele & $50(12.3)$ & $21(15.6)$ & 29 (10.7) & 0.16 \\
\hline Surgery of posterior colopocele & $18(4.4)$ & $7(5.2)$ & $11(4.1)$ & 0.61 \\
\hline Pelvic surgery & $126(31.1)$ & $51(37.8)$ & 75 (27.8) & 0.04 \\
\hline Hysterectomy (among women) & $90(24.0)$ & $42(33.6)$ & $48(19.2)$ & 0.002 \\
\hline Clinical characteristics & & & & \\
\hline Pelvic pain & $29(7.2)$ & $17(12.6)$ & $12(4.4)$ & 0.003 \\
\hline Bearing down & $26(6.4)$ & $13(9.6)$ & $13(4.8)$ & 0.06 \\
\hline Pelvic pain and/or bearing down & $53(13.1)$ & $29(21.5)$ & $24(8.9)$ & 0.003 \\
\hline Anal procidentia & $83(20.5)$ & $37(27.4)$ & $46(17.0)$ & 0.01 \\
\hline Genital procidentia\# & $57(14.1)$ & $22(16.3)$ & 35 (12.9) & 0.36 \\
\hline Syndrome rectal & $32(7.9)$ & $10(7.4)$ & $22(8.1)$ & 0.79 \\
\hline Digital assistance & $154(40.2)$ & $59(46.1)$ & $95(37.3)$ & 0.09 \\
\hline IBS (yes) & $214(52.8)$ & $83(61.5)$ & $131(48.5)$ & 0.01 \\
\hline Clinical dyssynergic defecation & $54(13.3)$ & $14(10.4)$ & $40(14.8)$ & 0.21 \\
\hline Enterocele (clinic examination) & $43(10.6)$ & $43(31.9)$ & $0(0.0)$ & 0.0001 \\
\hline Scores & & & & \\
\hline CCIS score $>8$ & $157(38.8)$ & $55(40.7)$ & $102(37.8)$ & 0.56 \\
\hline
\end{tabular}




\section{All $(N=405)$}

\section{Variable}

Kess score $>9$

GIQLI score
$N(\%)$ or mean (SD)

286 (70.6)

89.5 (23.8)
Enterocele ( $N=135)$

$N$ (\%)or mean (SD)

104 (77.0)

$90.0(26.1)$
No enterocele $(N=270)$

$N$ (\%) or mean (SD)

P-value

182 (67.4)

89.3 (22.6)
0.04

0.77

Abbreviations : $\mathrm{SD}=$ Standard deviation; $\mathrm{BMI}=$ Body Mass Index ; CCIS= Cleveland Clinic Incontinence Score; KESS= Knowles-Eccersley-Scott Symptom Constipation Score; GIQLI= Gastrointestinal Quality of Life Index; IBS= irritable bowel syndrome

Table 2 : Anorectal manometry and defecography

\begin{tabular}{|c|c|c|c|}
\hline & All $(N=405)$ & Enterocele $(N=135)$ & No enterocele $(N=270$ \\
\hline Variable & $N(\%)$ or mean (SD) & $N(\%)$ or mean (SD) & $N(\%)$ or mean (SD) \\
\hline
\end{tabular}

\section{Anorectal manometry}

Anal canal length (mm) (mmHg)

Lower part resting pressure $(\mathrm{mmHg})$

Mean squeeze duration (s)

Threshold perception volume (ml)

Constant perception volume (ml)

Maximum tolerable volume $(\mathrm{ml})$

Abdominal pressure during effort ( $\mathrm{mmHg}$ )

\section{Defecography}

Rectocele

Cystocele

Overt rectal prolapse

Resting perineal descent

Perineal descent during defecation effort

Rectal emptying $\geq 80 \%$

Rectal emptying (s)
$22.6(6.3)$

$32.4(17.9)$

$22.3(6.8)$

$31.0(18.7)$

47.7 (18.9)

$25.3(11.0)$

$17.8(19.9)$

$80.6(54.5)$

$190.8(86.9)$

$44.5(25.1)$

$42.1(26.6)$

$91(30.8)$

$176(47.8)$

$174(43.0)$

115 (28.5)

279 (69.2)

$231(57.2)$

$30.1(30.4)$

$37(27.4)$

60 (48.8)

82 (60.7)

53 (39.6)

111 (82.8)

62 (45.9)

27.3 (23.9)
22.7 (6.1)

0.59

$33.0(17.5)$

0.32

$28.9(13.0)$

0.97

26.8 (12.4)

0.23

18.6 (18.5)

0.70

$81.4(52.7)$

0.88

187 (81.7)

0.07

40.9 (26.4)

0.19

54 (20.0)

0.09

116 (47.4)

0.79

92 (34.1)

0.0001

62 (23)

0.0005

168 (62.5)

0.0001

$169(62.8)$

0.001

31.5 (32.8)

0.19 
Variable

Paradoxical puborectalis contraction
$N(\%)$ or mean (SD) $\quad N(\%)$ or mean (SD)

$N(\%)$ or mean (SD)

113 (28.0)

38 (28.4) 